\title{
Temporal and spatial variability of terrestrial diatoms at the catchment scale: controls on productivity and comparison with other soil algae
}

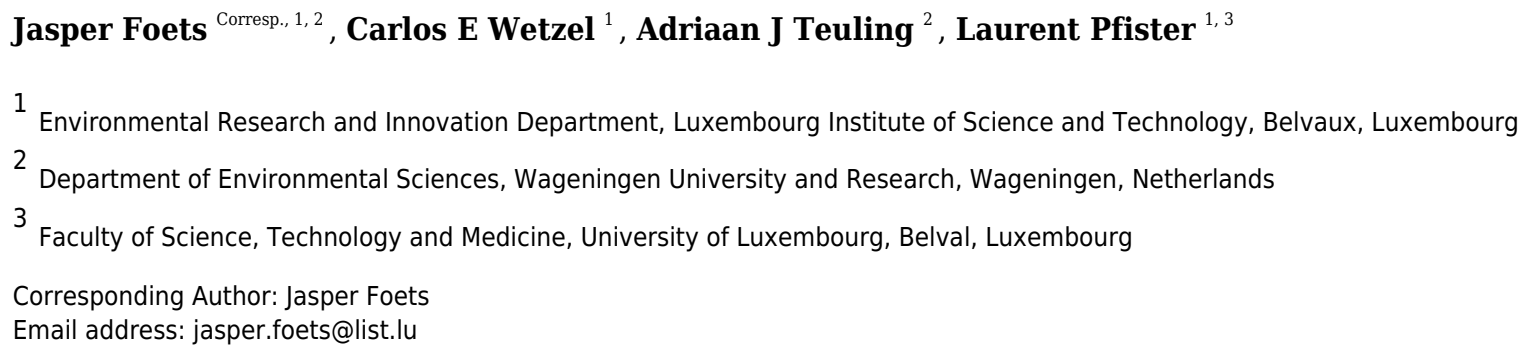

Terrestrial diatoms are an integral component of the soil microbial community. However, their productivity and how it compares to other algal groups remains poorly known. This lack of knowledge hampers their potential use as environmental markers in various applications. As a way forward, we investigated the seasonal and spatial patterns of diatom assemblages and the role of environmental factors on the soil diatom productivity. We collected soil algal samples in 16 sites across the Attert River basin (Luxembourg) every four weeks for a period of 12 months. The algal abundances were then derived from pigment analysis using High-Performance Liquid Chromatography (HPLC). Our results indicate that diatom productivity is mainly controlled by factors related to soil moisture availability leading to seasonal patterns, whereas the concentration of green algae remained stable over the course of the study period. Generally, anthropic disturbed habitats contained less living diatom cells than undisturbed habitats. Also, we learned that diatoms can be the dominant algal group at periods of the year with high soil moisture. 


\section{Temporal and spatial variability of terrestrial diatoms at the}

\section{2 catchment scale: controls on productivity and comparison with other}

3 soil algae

4 Jasper Foets ${ }^{1,2}$ Carlos E. Wetzel $^{1}$ Adriaan J. Teuling ${ }^{2}$ Laurent Pfister $^{1,3}$

$5 \quad{ }^{1}$ Environmental Research and Innovation Department, Luxembourg Institute of Science and

6 Technology, Belvaux, Luxembourg

$7{ }^{2}$ Department of Environmental Sciences, Wageningen University and Research, Wageningen,

8 Netherlands

$9{ }^{3}$ Faculty of Science, University of Luxembourg, Technology and Medicine, Belval,

10 Luxembourg

11

12 Corresponding Author:

13 Jasper Foets ${ }^{1}$

$14{ }^{1}$ Rue de Brill 41, Belvaux, L-4422, Luxembourg

15 Email address: jasper.foets@,1ist.lu 
17 Abstract

Terrestrial diatoms are an integral component of the soil microbial community. However, their productivity and how it compares to other algal groups remains poorly known. This lack of knowledge hampers their potential use as environmental markers in various applications. As a way forward, we investigated the seasonal and spatial patterns of diatom assemblages and the role of environmental factors on the soil diatom productivity. We collected soil algal samples in 16 sites across the Attert River basin (Luxembourg) every four weeks for a period of 12 months. The algal abundances were then derived from pigment analysis using High-Performance Liquid Chromatography (HPLC). Our results indicate that diatom productivity is mainly controlled by factors related to soil moisture availability leading to seasonal patterns, whereas the concentration of green algae remained stable over the course of the study period. Generally, anthropic disturbed habitats contained less living diatom cells than undisturbed habitats. Also, we learned that diatoms can be the dominant algal group at periods of the year with high soil moisture.

\section{Introduction}

Diatoms are microscopic, unicellular algae and form one of the most common and diverse algal groups in both freshwaters and marine environments (Round, Crawford, Mann \& 1990). They are pigmented, photosynthetic and because of their high abundances, they play a large role in the exchange of gasses between the atmosphere and biosphere. It has been estimated that they are responsible for $20 \%$ of the total oxygen production on the planet (Scarsini et al., 2019). While diatoms are generally regarded as inhabitants of water bodies, numerous taxa are able to survive and reproduce in a variety of terrestrial ecosystems such as soils, mosses, wet walls and rocks 
39 (Smol \& Stoermer, 2010). Generally, those environments are much harsher for diatoms than

40 aquatic habitats (Ress, 2012). Variables such as moisture and temperature can vary considerably

41 not only seasonally, but also over the course of a day or between two consecutive days. As a

42 consequence, diatoms are typically exposed to frequent and prolonged periods of desiccation.

43 Terrestrial diatom species have developed several features (both morphologically and

44 physiologically) to cope with the temperature variability and limited moisture conditions. For

45 instance, as the characteristic siliceous cell wall consists of many pores, they often decrease its

46 number or create structures to enclose them on the out- or inside to prevent water loss (Lowe et

47 al., 2007; Ress, 2012). This adaptability suggests that diatoms do not only survive on soils, but

48 that they eventually also could thrive and even be the dominant algal group in a terrestrial

49 environment.

As an integral component of the soil microbial community, diatoms play an important role in the

51 functioning of the soil ecosystem. By moving on or being attached to the soil surface, they

produce an extracellular matrix of mucopolysaccharides, which will bind soil particles and eventually stabilize the soil (Booth, 1941; Paterson, 1986; Tolhurst, Gust \& Paterson, 2002; Jewson, Lowry \& Bowen, 2006). This aggregation will subsequently reduce water loss by evaporation, limit soil erosion and improve water infiltration, thereby providing a favorable habitat for seed germination (Booth, 1941; Hoffmann, 1989). Moreover, they promote the release of nutrients from insoluble compounds and the weathering of silicates by creating a slightly

58 acidic environment (Hoffmann, 1989; Wu et al., 2013). Schmidt, Dyckmans \& Schrader (2016) found that they even might be an important carbon input source for decomposing soil animals. Their death and decay also provides organic matter, which other microorganisms and plants can potentially utilize (Fritsch, 1907; Shubert \& Starks, 1979; Starks, Shubert \& Trainor, 1981). As 
62 climate change is highly likely to increase the frequency and persistence of droughts in the near

63 future (Berg \& Sheffield, 2018), there is growing concern about potential negative impacts that

64 this change could have on the viability and functions of terrestrial diatoms and subsequently also

65 on higher plants.

66

67

68

In temperate regions, the seasonal variability in meteorological (e.g. humidity), chemical (e.g. nutrients) or biological conditions (e.g. vegetation height) is not causing any significant changes in the composition of soil diatom communities according to Lund (1945) and Foets et al. (2020). However, seasonal variations might prevail in the diatom biomass with possible maxima observed in spring and autumn in response to changes in temperature and precipitation (Lund, 1945). A similar observation for soil algae was reported by Stokes (1940), who noticed sharp increases in algal numbers after periods of rain and that the optimum moisture range for algal growth lies between 40 and $60 \%$ of the moisture-holding capacity of the soil. This amount would probably be ideal to produce a soil solution with enough available nutrients to support algal growth (Pringsheim, 1950; Starks \& Shubert, 1982). Furthermore, Davey (1991) and Grondin \& Johansen (1995) reported an increased algal biomass (in algal numbers and in chlorophyll a concentration) after snow cover. Although Lund (1945) is the only study (of all aforementioned studies) to date to have analyzed specifically the terrestrial diatom production, the temporal and spatial scale of that study was relatively limited (i.e. one garden soil in optimal conditions).

There is a pressing need for a better understanding of the seasonal patterns in diatom production across contrasted environmental settings. This stands as a prerequisite for their subsequent use in future applications (e.g. as soil quality bio-indicator or as a hydrological tracer).

Algae and cyanobacteria use pigments and other compounds to regulate the spectral composition and the intensity of incoming light (photon flux density). This allows them to maximize 
85 photosynthetic efficiency whilst preventing photochemical degradation of cellular components

86 and indirect loss of function mediated by reactive oxygen species (Vincent, 2000). Two types of

87 pigments are involved in those processes. Chlorophylls, particularly a, b and c, are the central

88 components in light-harvesting, while carotenoids, including xanthophylls, are mainly engaged in photoprotection (Demmig-Adams \& Adams, 2000). In contrast to higher plants, which all contain the same major carotenoids, algae have different characteristic carotenoids. So far, around 1100 different natural carotenoids have been characterized and reported in the literature (Fernandes et al., 2018). This diversity and specificity allows us to use certain carotenoids as socalled biomarkers or chemotaxonomical markers to infer the production of different algal groups. Furthermore, recent developments in High-Performance Liquid Chromatography (HPLC) allow for rapid and accurate determinations of pigments and their derivatives in aquatic and sediment samples. Pigment concentrations have now become a common tool in paleolimnological research and water quality assessments (Verleyen et al., 2004; Reavie et al., 2017; Duong et al., 2019). However, except for a few studies on soil primary production (Shubert \& Starks, 1979; Starks \& Shubert, 1982; Davey, 1991; Davey \& Rothery, 1992), no other attempts have been reported to date to assess soil diatom production and its environmental controls.

Previously, we have investigated the temporal and spatial variability in the composition of soil diatom communities (Foets et al., 2020). There, we found that forests create a stable microhabitat for diatoms, that the temporal variation of the communities is mainly controlled by farming practices, and that they need one to two months to reestablish a new, stable community after a significant change in the environment. Here, we leverage these findings and investigate how diatom production changes over space and time in a mesoscale catchment 107 compared to green algae and cyanobacteria. The catchment scale was selected, since this is the 
108 natural unit in which environmental variables such as radiation, temperature and soil moisture

109 show the largest variability. The aim of this study is mainly exploratory, but while analyzing the

110 data for Foets et al. (2020), we also developed two hypotheses. Our first hypothesis states that

111 soil diatom productivity (i.e. concentration of fucoxanthin) is controlled by meteorological

112 conditions. Our second hypothesis stipulates that the biomass changes depending on the type of

113 habitat, since communities in (anthropic) disturbed areas contain generally larger species (i.e.

114 higher pigment concentration) compared to undisturbed areas (Foets et al., 2020).

\section{Material and methods}

\section{Study area and weather conditions}

117 Our study site is located in the Attert River basin in Luxembourg, covering an area of approximately $249 \mathrm{~km}^{2}$ (Fig. 1). The western limit of the basin extends into Belgium

$119\left(49^{\circ} 46^{\prime} 13.0^{\prime \prime} \mathrm{N}, 5^{\circ} 59^{\prime} 9.2^{\prime \prime} \mathrm{E}\right)$. Additional information on the study area is given in Foets et al. 120 (2020).

121 We took monthly samples from December 2017 to November 2018. The summer season prior to

122 the start of our sampling campaign had been relatively wet (on average $88 \mathrm{~mm} / \mathrm{month}$; i.e. 32

$123 \mathrm{~mm} / \mathrm{month}$ more than in reference period 1981-2010), whereas the average monthly precipitation

124 during the sampling period was $56.8 \pm 33.5 \mathrm{~mm}$. The maximum monthly precipitation was

125 observed in December 2017 and January 2018 (111.9 and $123.5 \mathrm{~mm}$, respectively). Monthly

126 precipitation reached a minimum in October $2018(18 \mathrm{~mm})$. July and August were the warmest

127 months, reaching mean monthly temperatures of $20.5^{\circ} \mathrm{C}$ and $18.7^{\circ} \mathrm{C}$, respectively. Most

128 freezing days occurred in February and March 2018 (28 and 12, respectively) [Data obtained

129 from the 'Administration des Services Techniques de l'Agriculture' (ASTA)]. Overall, 2018 was 
130 characterized by a cold winter and an exceptionally dry and warm summer period (Meteolux, 131 2019).

\section{Meteorological data}

133 Daily meteorological data for the entire study period was retrieved from two weather stations 134 (Useldange and Roodt) situated in the river basin. All data was taken from Useldange, except 135 daily precipitation. For that, we calculated Thiessen polygons to know which sites were closer to 136 which station. Besides, we derived air temperature for every site following the general equation: $137-0.65^{\circ} \mathrm{C} \times 100 \mathrm{~m}$ (Altitude). The station in Useldange is located at $280 \mathrm{~m}$ a.s.l. Additionally, $2^{\circ} \mathrm{C}$ 138 were deducted for the forested sites. Finally, the 7-day average prior to the sampling day was 139 taken for every meteorological variable.

\section{Soil sampling and pigment analysis}

141 In order to capture the intra-annual and spatial variability of the absolute algal abundances, we

142 took soil samples at the soil surface in 16 sites distributed across the Attert River basin (see Foets 143 et al., 2020). The sampling campaigns took place every three to five weeks for a period of 12 144 months $(\mathrm{n}=192$ samples). During each campaign, we made a description of the site in order to 145 keep track of any potential changes in the environment in between the sampling periods.

146 Characteristics such as type of land use, disturbances, height of the lower vegetation (we used 147 grass height as an indicator for mowing/grazing) were noted (see Table A1). In addition, we 148 measured soil moisture content and electrical conductivity (EC) 30 times, using a FieldScout 149 TDR 300 Soil Moisture Meter. Moreover, out of the four soil samples that we took per site, one 150 was to serve for pigment analysis and one was used for species community analysis (see Foets et 151 al., 2020). 
152 We used metal cylinders (Ø: $5.6 \mathrm{~cm}$, height: $4 \mathrm{~cm})$ to collect small soil cores. Upon arrival in the

153 lab, all plant litter was carefully removed from the top soil layer to keep the sample undisturbed.

154 We then extracted algae by rinsing the superficial layer with Milli-Q water until a $50 \mathrm{~mL}$ falcon

155 tube was completely filled (see Barragán, Wetzel \& Ector, 2018). The samples, consisting of soil

156 particles and water, were kept in the dark at $4^{\circ} \mathrm{C}$ until pigment extraction.

157 The following day, we centrifuged the samples for 10 minutes at $4000 \mathrm{rpm}$. We discarded the

158 supernatants and freeze-dried the residues for approximately 24 hours. Next, we extracted the

159 pigments two times with $5 \mathrm{~mL}$ methanol by shaking for 15 minutes at $25 \mathrm{~Hz}$. with a mixer mill

160 (MM 400 Retsch). After centrifugation (4000 rpm., $10 \mathrm{~min}$ ), organic phases were pooled and

161 extracts were concentrated by vacuum evaporation.

162 We separated and quantified the pigments by HPLC with Diode-Array Detection (HPLC-DAD,

1631260 Infinity, Agilent). An Acquity UPLC HSS T3 column at $30^{\circ} \mathrm{C}$ was used $(2.1 \times 100 \mathrm{~mm}, 1.7$

$164 \mu \mathrm{m}$ ) with a mobile phase consisting of 50mM ammonium acetate solution,

165 acetonitrile/dichloromethane/methanol (75/10/15 v/v/v), and ethyl acetate. Pigments were eluted

166 at a flow rate of $300 \mu \mathrm{L} \mathrm{min}{ }^{-1}$ with a ternary gradient. We identified the compounds of interest

167 by their retention time and compared the spectral data with certified standards provided by

168 Sigma-Aldrich and Carotenature. The detection limit for the standards was $30 \mathrm{ng}$ per sample.

169 Quantification was done at 450, 464, 620 and $655 \mathrm{~nm}$ using external calibration. We expressed

170 chlorophyll and carotenoid concentrations in ng per sample $(50 \mathrm{~mL})$ and transformed them to $\mu \mathrm{g}$

$171 \mathrm{~L}^{-1}$ to make the concentrations comparable with other studies. The different pigments used in the 172 analysis, their affinity and interpretation are listed in Table 1.

\section{Physico-chemical analysis}


174 After the algal extraction, we removed the first $\mathrm{cm}$ of soil of each of the four samples. After

175 having dried the samples for one week at room temperature, we crushed the soils and sieved

176 them at $2 \mathrm{~mm}$. We measured the $\mathrm{pH}$ according to the ISO 10390 (2005) standard. The

177 bioavailable part of nutrients (phosphorus $(\mathrm{P})$, total nitrogen $(\mathrm{TN})$, dissolved organic carbon

178 (DOC), silica $(\mathrm{Si})$, magnesium $(\mathrm{Mg})$, manganese $(\mathrm{Mn})$, sodium $(\mathrm{Na})$, potassium $(\mathrm{K})$, iron $(\mathrm{Fe})$

179 and aluminum (Al)) were all extracted following the method described by Houba et al. (2000).

180 We added $150 \mathrm{~mL}$ of $0.01 \mathrm{M} \mathrm{CaCl}_{2}$ to $15 \mathrm{~g}$ of soil in a $250 \mathrm{~mL}$ glass bottle and shook this

181 mixture for two hours. Next, we centrifuged the samples for 15 minutes at $5000 \mathrm{rpm}$. The

182 supernatant was filtered through $0.7 \mu \mathrm{m}$ glass microfiber filters and stored at $4^{\circ} \mathrm{C}$ prior to the

183 ICP-OES (5110 VDV radial, Agilent) analysis of P, Mg, Mn, K, Si and Na. DOC and TN

184 concentrations were determined directly after the extraction with a Torch Combustion TOC/TN

185 analyzer (Teledyne Tekmar). With a view to Fe and Al content analysis, we additionally filtered

$18610 \mathrm{ml}$ of the supernatant with $0.45 \mu \mathrm{m}$ syringe filters (Acrodisc ${ }^{\circledR}$, Pall) and added $100 \mu \mathrm{L} 1 \mathrm{M}$

$187 \mathrm{HCl}$ before the ICP-MS (Thermo Elemental X7/Perkin-Elmer ${ }^{\odot}$ DRC-e) analysis, but the free

188 metal ions concentrations were not estimated.

\section{Scanning electron microscope analysis}

190 We carried out a scanning electron analysis to get information regarding diatoms within the soil 191 matrix (e.g. their abundance, their way of living). Additional soil samples were taken in

192 November 2017 at an agricultural grassland site (site 9, see Foets et al. 2020). We carefully

193 placed a part of the soil samples on aluminum stubs and analyzed them with a Quanta 200 Field

194 Emission Gun Scanning Electron Microscope (FEG SEM) (Phillips-FEI). In addition, the

195 microscope was equipped with a Genesis XM 4i Energy Dispersive Spectrometer (EDS) system 
196 for chemical analysis. For complementary EDS analysis, we used a large field detector, as our

197 examination was done in a low-vacuum environment $(150 \mathrm{~Pa})$.

\section{Statistical analyses}

199 Based on meteorological and discharge datasets, we calculated two soil moisture availability

200 proxies for the Attert River basin. First, we inferred daily water storage deficits (SD) from water

201 balance calculations as per Pfister et al. (2017). Second, we calculated daily differences between

202 precipitation input and potential evapotranspiration loss (PET). We used the FAO Penman-

203 Monteith equation for calculating PET (Allen et al., 1998). For these calculations, we assumed

204 the soil heat flux to be zero and the psychrometric constant equal to 0.065 .

205 Correlations between continuous environmental variables and between pigment concentrations

206 were assessed using Spearman rank correlation. One of each correlated (i.e. $\mathrm{R}^{2}>0.5$ or $<-0.5$ )

207 environmental variable was retained for further discriminant analyses (see results section). Also,

208 possible spatial autocorrelation of the pigment measurements was assessed with a Mantel test.

209 For doing that, pigment data were transformed to a dissimilarity matrix (Bray-Curtis) and tested

210 if there was significant correlation (perm-999) with the geographical distance matrix. The latter

211 was obtained using the rdist.earth function from the R-package fields (Nychka et al., 2017).

212 Before carrying out the indirect and direct ordination analysis, pigment data was Hellinger-

213 transformed. Detrended correspondence analysis (DCA) on the pigment data revealed a gradient

214 length smaller than 2.0 S.D. (standard deviation) (Hill \& Gauch, 1980). Therefore, we relied on a

215 redundancy analysis (RDA) as an exploration method.

216 We used the variation partitioning technique (Legendre, Borcard \& Peres-Neto, 2005) to

217 quantify the relative contributions of three matrices of variables (soil chemistry, meteorology,

218 and site characteristics) to the explained variance and to test whether and to what extent their 
219 contributions to the composition of the pigment concentrations could be separated. Testable

220 fractions were analyzed with RDA. For testing our first hypothesis, we carried out a multiple

221 regression analysis on the fucoxanthin data to identify the variables that are significantly related

222 to diatom abundances. A generalized mixed model (lmer function) was formed with 'site' as a

223 random variable to account for repeated measurements. Prior to model building, fucoxanthin

224 concentrations were log-transformed $(x+0.0001)$ to get normal distributed data and

225 environmental variables were rescaled. We did variable selection with backward elimination

226 using the step function from the lmerTest package (Kuznetsova, Brockhoff, Christensen, 2017).

227 Afterwards, the residuals of the final model were checked. For testing our second hypothesis, we

228 calculated diatom biovolume by multiplying the raw diatom community data given in Foets et al.

229 (2020) with the species size measurements given in Rimet \& Bouchez (2012) and Omnidia

230 (version 6.0.8, 2018) (Lecointe, Coste \& Prygiel, 1993). Next, we tested the variability of

231 biovolume and pigment concentrations over qualitative variables (e.g. month, soil and habitat

232 type) with analysis of variance (ANOVA), whilst accounting for repeated measurements, or the

233 non-parametric Kruskal-Wallis test. Homoscedasticity was checked with the Breusch-Pagan test.

234 Thereafter, we analyzed more specifically the significant results by relying on Tukey's range or

235 the pairwise Wilcoxon test, respectively. All aforementioned statistical analyses were performed

236 using the R statistical program (R v. 3.5.3.; http://www.r-project.org/) and additional functions

237 from the R-package vegan version 2.5-5 (Oksanen et al., 2019).

\section{Results}

239 Soil Matrix

240 Diatoms live at the top of the soil surface and with 15 cells per approximately $0.2 \mathrm{~mm}^{2}(=7500$

241 cells $\mathrm{cm}^{-2}$ ) diatoms are relatively abundant even on a small area such as shown in Fig. 2B. The 
242 occurring species are mainly Nitzschia pusilla (Kützing) Grunow emend. Lange-Bertalot,

243 Sellaphora nana (Hustedt) Lange-Bertalot, Cavacini, Tagliaventi \& Alfinito and Hantzschia

244 amphioxys (Ehrenberg) Grunow. Bacilli-shaped bacteria are also present at the soil surface (Fig.

245 2C). However, because they are so small, it is impossible to see whether the bacteria are

246 cyanobacteria or not. Green algae are absent on the picture. This general observation is supported

247 by the average pigment concentrations measured on that particular site (site 9), which indicate

248 that diatoms on average $\left(9.0 \mu \mathrm{g} \mathrm{L}^{-1}\right)$ are more abundant than green algae $(2.6 \mu \mathrm{g} \mathrm{L}-1)$ and

249 cyanobacteria $\left(0.7 \mu \mathrm{g} \mathrm{L}^{-1}\right)$.

250 Besides the topography, the SEM picture also gives an idea of the chemical composition of the

251 top layer (Table 2). The contrast of the picture is based on the convention that "heavier"

252 elemental areas (= higher atomic number) are shown in light grey and low atomic number

253 elements in darker grey. Our subsequent analysis showed that the percentage of carbon and

254 oxygen in $H$. amphioxys is much higher than at the soil surface (difference of respectively \pm 100

255 and 50\%), while the silica concentration is approximately the same. Interestingly, the aluminum

256 concentration at the soil is high (11.0\%) compared to the other elements and around a third of

257 that percentage is found in the diatom (3.4\%). In addition to the composition mode, chemical

258 maps could be made displaying the chemical contrast in a colored pixel map (Fig. 2G - I). This

259 means that the higher the elemental concentration is, the higher the colored pixel density will be.

260 Since oxygen and silica had the highest concentrations, they gave the best pixel maps of all

261 present chemical elements. While the map of silica is only able to show us roughly the contours

262 of $H$. amphioxys, some differences in the external valve structure are visible on the oxygen map.

\section{Controlling environmental variables}


264 Chlorophyll a (cf. primary production (Table 1)) had the highest average concentration over the 265 sampling campaign $\left(12.7 \pm 13.5 \mu \mathrm{g} \mathrm{L}^{-1}\right)$, followed by lutein (cf. green algae) and fucoxanthin (cf. 266 diatoms), with concentrations of $5.7 \pm 10.0 \mu \mathrm{g} \mathrm{L}^{-1}$ and $5.0 \pm 8.2 \mu \mathrm{g} \mathrm{L}^{-1}$, respectively. We

267 determined the lowest average concentrations in zeaxanthin (cf. cyanobacteria; $1.1 \pm 1.5 \mu \mathrm{g} \mathrm{L}^{-1}$ )

268 and diatoxanthin $\left(0.6 \pm 0.3 \mu \mathrm{g} \mathrm{L}^{-1}\right)$. However, the differences between the concentrations of

269 fucoxanthin and lutein were not significant when considering the whole dataset (Wilcoxon test, P $270=0.089)$, whereas the concentrations of zeaxanthin were significantly different for both

271 fucoxanthin and lutein $(\mathrm{P}<0.001)$. This finding is confirmed when comparing the different

272 habitat types with each other (Fig. 3A). In addition, the figure shows that the type of habitat does

273 not have an influence on those three algal groups (Kruskal-Wallis, $\mathrm{d} f=4, \mathrm{P}>0.05$ ). However,

274 diatom biovolume significantly differs between the different habitats with disturbed areas having

275 generally smaller communities than undisturbed habitats (ANOVA, d $f=4, \mathrm{P}<0.001$ ) (Fig. 3B).

276 Results of the correlation analyses showed that the environmental descriptors, physico-chemical

277 and meteorological variables were not correlated between each other $\left(\mathrm{R}^{2}\right.$ not higher than 0.5 for

278 all the variables $)$. DOC and $\mathrm{TN}\left(\mathrm{R}^{2}=0.58\right)$ and $\mathrm{EC}$ and moisture $\left(\mathrm{R}^{2}=0.91\right)$ were correlated.

279 Furthermore, most of the meteorological variables were correlated with each other $\left(\mathrm{R}^{2}>0.5\right.$ or $<$

$280-0.5)$ and as a result, only radiation and SD of the meteorological variables were included in the

281 RDA analysis, while K and EC were removed. Concerning the different pigments, fucoxanthin

282 was correlated with diadinoxanthin $\left(\mathrm{R}^{2}=0.64\right)$, while lutein was positively correlated with

283 zeaxanthin $\left(\mathrm{R}^{2}=0.59\right)$ and with total chlorophyll a $\left(\mathrm{R}^{2}=0.58\right)$.

284 There was no indication of spatial autocorrelation in the pigment data according to the Mantel 285 tests $(\mathrm{P}>0.05)$. The total variation explained by the RDA was $40 \%$. The first two RDA axes 286 covered respectively 40 and $5 \%$ of the total explained variation. However, only the first axis 
287 resulted as significant $(\mathrm{P}=0.001$ and 0.158 respectively) after permutation test. In the $2 \mathrm{D}$

288 ordination, fucoxanthin and lutein are mainly related to the first axis, which is determined by

289 radiation, $\mathrm{TN}$ and $\mathrm{SD}$, while the other carotenoids follow more the second axis, which is

290 correlated with soil moisture content (Fig. 4). Of those mentioned variables, most exhibit a

291 strong seasonal gradient (e.g. radiation, soil moisture and SD). The Venn diagram (Fig. 5) shows

292 that meteorological variables explain in total (including joint effects) $23.7 \%$ of the total variation

$293(\mathrm{~F}=3.80, \mathrm{~d} f=7, \mathrm{P}=0.02)$, whereas the site characteristic variables and soil chemical factors

294 explain respectively $13.3(\mathrm{~F}=2.88, \mathrm{~d} f=5, \mathrm{P}=0.01)$ and 9.1\% $(\mathrm{F}=2.57, \mathrm{~d} f=11, \mathrm{P}=0.027)$.

295 However, only $37.7 \%$ of the variation could be explained. Furthermore, multiple regression

296 analysis revealed that diatom productivity (log-transformed) has a strong seasonal gradient with

297 radiation, $\mathrm{SD}$, and vegetation height all significant (ANOVA, $\mathrm{F}>8.73, \mathrm{P}<0.05$ ), whereas $\mathrm{pH}$ is

298 an important factor $(\mathrm{F}=31.49, \mathrm{P}<0.001)$ in creating a spatial gradient. Besides, diatom

299 productivity is positively correlated with $\mathrm{pH}$ and vegetation height, whereas a negative relation

300 with radiation and SD exist.

301 Spatial and temporal variability pigment concentrations and diatom biovolume

302 Diatom abundance shows a strong seasonal variability with a peak in February and March (Fig.

303 6B), which occurred after the two wettest months and coincides with the coldest period of the

304 sampling campaign. In the subsequent spring and summer period (April-September), abundances

305 are low with an average of $3.9 \mu \mathrm{g} \mathrm{L}^{-1}\left( \pm 3.8 \mu \mathrm{g} \mathrm{L}^{-1}\right)$ per month. A slight increase is again visible

306 in November. In contrast to the diatoms, green algae show less seasonality and their

307 concentrations remain relatively high throughout the whole campaign. Furthermore, chlorophyll

308 a reaches its highest concentrations in February and March following the pattern of fucoxanthin

309 (Fig. 6C). Also, a peak occurred in June reaching on average $24.0 \mu \mathrm{g} \mathrm{L}^{-1}$ while experiencing a 
310 precipitation of $90.8 \mathrm{~mm}$ that month. The lowest average chlorophyll a concentrations were

311 measured at the beginning of the campaign in December and January $\left(2.7\right.$ and $4.1 \mu \mathrm{g} \mathrm{L}^{-1}$

312 respectively).

313 Since larger diatoms generally contain more pigments, the diatom biovolume was calculated to

314 check if the temporal variability of the fucoxanthin concentration was influenced by their cell

315 size. Opposed to the fucoxanthin concentration, the diatom biovolume did not change

316 significantly during the year (ANOVA, $\mathrm{F}=2.29, \mathrm{~d} f=11, \mathrm{P}>0.05$ ) (Fig. 6C), meaning that the

317 temporal variability in the fucoxanthin concentration is not related to the absolute size of the

318 diatom community. Finally, in Fig. 6D the ratio between the photoprotective carotenoids in

319 diatoms (i.e. diadinoxanthin and diatoxanthin) and the light harvesting pigment fucoxanthin is

320 given. This ratio generally follows the pattern in radiation/temperature levels during the year. In

321 summer, diatoms sometimes had twice the amount of photoprotective pigments than fucoxanthin

322 during summer time, whereas in winter the average ratio was less than or equal to one in the first

323 three months of study campaign (Kruskal-Wallis, $\mathrm{d} f=11, \mathrm{P}<0.001$ ).

\section{Discussion}

\section{Soil microbial community}

326 The SEM image of the soil surface showed a diverse microbial community. Both diatoms and

327 (cyano)bacteria were present. Surprisingly, green algae seemed absent. Generally, green algae

328 are an important part of the soil algal community (Starks, Shubert \& Trainor, 1981; Rindi, 2011),

329 which our pigment data also confirms. However, for that agricultural grassland site our data

330 indicated that usually diatoms are more abundant than green algae during the period the sample

331 was taken (i.e. November). Besides, species of the algal classes Xanthophyta, Rodophyta and 
332 Euglenophyta could also be present on soils. However, they generally occur in low abundances.

333 Therefore, we did not expect to see them on the picture. Despite that pigment concentrations

334 could be a good estimate for algal abundances, the amount of each pigment per algal cell is also

335 dependent on its size (i.e. larger cells have a higher amount of each pigment). Overall, terrestrial

336 diatoms and green algae have similar cell sizes (Rindi et al. 2011; Ress et al. 2012), whereas

337 cyanobacteria have on average smaller dimensions. Therefore, the pigment signal is lower for the

338 same number of living cells. This could explain why there are (cyano)bacteria present whilst

339 having a lower pigment concentration than green algae. Thus, for pigment analysis, size does

340 matter and this makes it difficult to compare pigment data with algal counts.

\section{Spatial and temporal variability in relation to environmental factors}

342 In this study, we analyzed 25 environmental variables and related them to the different

343 concentrations of fucoxanthin over the entire 12-month study period. Of those 25 , we found that

$344 \mathrm{pH}$, radiation, $\mathrm{SD}$ and height of the lower vegetation were significant in explaining $45 \%$ of the

345 variability in diatom productivity. The relation with $\mathrm{pH}$ was positive, suggesting that diatoms

346 prefer higher $\mathrm{pH}$ values. This is in agreement with an earlier work by Hoffmann (1989),

347 indicating that most diatoms reach their highest abundances on neutral to alkaline soils.

348 However, our maximum soil $\mathrm{pH}$ extended only to 8.11 , meaning that we were unable to conclude

349 on an optimum occurring or not. Regarding radiation and $\mathrm{SD}$, both variables can serve as a proxy

350 for soil moisture availability. The negative relation between those factors and fucoxanthin

351 concentration was therefore expected since water, which is often a limiting factor, is essential for

352 diatom survival and reproduction (Camburn, 1982; Van de Vijver, Ledeganck \& Beyens, 2002).

353 We also noticed that SD was a better factor for explaining the temporal and spatial variability in

354 the concentration of fucoxanthin than precipitation and soil moisture content. This is probably 
355 because it takes both variables into account. In this case, soil moisture was a point measurement

356 and does not give any information of the antecedent conditions, while precipitation (average of

357 seven days prior to sampling day) does not inform on how much water is still prevailing in the

358 upper soil layers. Finally, we found a positive relation between vegetation height and diatom

359 abundances. This could indicate that the capacity of a higher vegetation to better keep moisture

360 and protect against UV-radiation is important for diatom growth - particularly in warm and dry

361 conditions (Ress, 2012; Zhang, Lv \& Pan, 2013). Despite having analyzed many different

362 environmental factors, we were still not able to explain a large part of the variation.

363 We observed maxima in the chlorophyll a concentration in winter and in June, following

364 month(s) of high precipitation. Stokes (1940) reported the same observation and considered the

365 antecedent moisture conditions as responsible for the high abundances in summer. Regarding the

366 peak during winter, he considered snow cover as being important for algal growth and

367 conjectured that a blanket of snow keeps the soil moist and warmer than the surrounding

368 atmosphere - creating favorable conditions for algal development. However, the results of Davey

369 (1991) and Grondin \& Johansen (1995) refute the latter, since the disappearance of snow led

370 instead to a steep increase in the algal concentration. Although we encountered snowfall during

371 February and March, the snow layer did not prevail for long. Thus, our winter peak could be

372 rather the result of changes between the presence and absence of snow cover, so that soil algae at

373 one point in time are protected against harsh winter conditions and at another point, they are able

374 to maintain photosynthesis. An additional reason for the winter peak could be that under those

375 low light conditions soil algae maximizes their chlorophyll a content to optimize their

376 photosynthetic activity and decrease their chlorophyll content under high-irradiance conditions in

377 summer (Neidhardt et al., 1998; Quesada \& Vincent, 1993; Bohne \& Linden, 2002). Indeed, 
378 according to Kuczynska, Jemiola-Rzeminska \& Strzalka (2015) those changes are usually fast

379 since they are engaged in basic processes (e.g. photosynthesis and photoprotection), which are

380 essential for cell life. Thus, seasonality in chlorophyll a concentration is probably the result of

381 the algal growth in combination with their physiological state. In addition, chlorophyll a

382 comprises different algal groups which could respond in a different way to varying

383 environments.

384 Indeed, diatoms and green algae reacted differently to seasonal conditions. While diatoms

385 exhibited very high abundances in winter and lower abundances during summer, the abundances

386 of green algae remained high throughout the sampling period. This indicates that green algae are

387 more tolerant to dry and warm environmental conditions than diatoms. The reasons for this could

388 lie in the mucilage production and the cell aggregation ability (e.g. forming filaments) of soil

389 green algae. It is known that for green algae the extracellular matrix is well resistant against

390 periods of desiccation and could contain a considerable amount of moisture (up to $97 \%$ of the

391 total weight) (Boney, 1980; Shephard, 1987; Rindi, 2011). Furthermore, by forming filaments,

392 they support a high self-protection against water loss (Karsten \& Holzinger, 2014). Although

393 many soil diatom species have developed adaptations to fluctuating moisture availabilities in

394 terrestrial habitats (including the production of a mucopolysacharide matrix), the adaptations

395 made by terrestrial green algae seem to be more efficient (Shephard, 1987; Ress, 2012).

396 Despite the fact that diatom abundances are strongly related to moisture availability, the latter

397 obviously does not affect the diversity and composition of their assemblages. Johansen (1993)

398 observed high diatom diversity in arid environments, whereas, in a related study by Foets et al.

399 (2020), diatom composition and diversity did not change significantly during the year. In

400 addition, the latter also showed that diatom communities have a strong spatial component and are 
401 controlled by the amount of anthropic disturbance with larger species often being more tolerant

402 (cf. H. amphioxys, Pinnularia borealis Ehrenberg). Such observations were also visible in the

403 results of our biovolume calculations. However, there were no spatial differences in fucoxanthin

404 concentrations, meaning that overall less living diatom cells are present in disturbed compared to

405 undisturbed areas. On the contrary, the temporal variation in the measured fucoxanthin

406 concentration is not influenced by the diatom biovolume, since the results of the biovolume did

407 not show any temporal variation. Additionally, like chlorophyll, fucoxanthin has an important

408 function in light-harvesting and its concentration is therefore affected in the same way as

409 chlorophyll by different irradiance levels (Xia et al., 2013; Kuczynska, Jemiola-Rzeminska \&

410 Strzalka, 2015). Because of that, we would expect the differences in the number of living diatom

411 cells between the summer and winter period to be smaller than what we would expect from the

412 results derived from the pigment analysis. Besides the fact that the size and physiological state of

413 diatoms are important for pigment concentration, we could conclude that the distribution of

414 diatom communities is mainly controlled by spatial factors related to the amount of disturbance

415 and that diatom abundances are generally linked to temporal factors related to (soil) moisture

416 availability.

\section{Recommendations and perspectives}

418 Pigment analyses proved to be a useful tool in identifying microbial communities and deriving 419 their abundances (Leavitt \& Hodgson, 2001). Here, we applied the same algal extraction method 420 as described in Barragán, Wetzel \& Ector (2018) for diatom community analysis. However, it is

421 recommended by the authors that only samples of bare soil or with only low presence of grass or

422 other vegetation are taken. This is because dense vegetation does not allow a proper rinsing of

423 the soil substrate and subsequently hinders the detachment of algal communities. As we followed 
424 this recommendation, we believe that we equally extracted the different algal groups.

425 Furthermore, we used average diatom biovolume measurements taken from aquatic specimens

426 (including terrestrial species occurring in those habitats). However, previous studies of Van de

427 Vijver \& Beyens (1997), Ress (2012) and Stanek-Tarkowska et al. (2013) all reported that cell

428 sizes could be significantly different (both larger and smaller) between terrestrial and aquatic

429 habitats. We did not incorporate this, but as those changes are not unidirectional, we believe that

430 there would only be a minimal effect on some of the results. Besides, we were not able to

431 compare our pigment concentrations with other studies, since many different preparation,

432 extraction and analytical methods are used and subsequently pigment concentrations are

433 expressed in different units (e.g. $\mu \mathrm{g} \mathrm{L}^{-1}, \mathrm{mg} \mathrm{cm}^{-2}, \mathrm{mg} \mathrm{g}^{-1}$ soil) (Leavitt \& Hodgson, 2001;

434 Cartaxana \& Brotas, 2003; Schagerl \& Künzl, 2007; Kuczynska, Jemiola-Rzeminska \& Strzalka, 435 2015).

436 Moreover, only few studies exist on the ecology of terrestrial diatoms compared to aquatic

437 diatoms. This is rather surprising, since terrestrial diatoms and other algae are arguably affected

438 more directly than aquatic algae by climatic changes and can be expected to respond in an

439 immediate way (Rindi, 2011; Ress, 2012; Souffreau et al., 2013). Therefore, future research

440 should give more attention to terrestrial microbial communities, certainly in the light of climate

441 change.

442 Conclusions

443 In this study, we investigated the temporal and spatial variability of soil diatom abundances and

444 compared them with the abundances of green algae and cyanobacteria. The abundances were

445 derived from pigment analysis using HPLC. Our results supported our first hypothesis that

446 diatom abundances show seasonal succession and that their abundances are mainly controlled by 
447 factors influencing the (soil) moisture availability (e.g. radiation and storage deficit). However, 448 our second hypothesis was rejected, since the effect of habitat type, which played a key role in 449 shaping the diatom communities (Foets et al., 2020) and subsequently their biovolume, was not 450 seen in the pigment concentrations. This led to the conclusion that overall less diatom cells are 451 present in disturbed than in undisturbed habitats. Contrary to diatoms, green algal productivity 452 remained stable over the course of the study period. Also, we observed that diatoms could have 453 higher abundances than green algae and cyanobacteria at periods of the year with high soil 454 moisture. Concerning future studies, more focus should be on the ecology of terrestrial diatoms 455 and other algae, since they are affected more directly than aquatic algae by climatological 456 conditions (Rindi, 2011; Hinder et al., 2012).

\section{Acknowledgements}

458 The authors are very grateful to Emmanuelle Cocco for the pigment analysis and developing the protocol. They also thank Dr. Denis Pittois and Johanna Ziebel for analyzing the soil nutrients.

460 Three reviewers are thanked for their constructive comments that significantly improved the 461 manuscript.

\section{References}

463 Allen, R.G., Pereira, L.S., Raes, D., Smith, M., Ab, W., 1998. Crop evapotranspiration: guidelines for computing crop water requirements, FAO Irrigation and drainage paper, Food and Agriculture Organization of the United Nations. Rome. https://doi.org/10.1016/j.eja.2010.12.001 terrestrial diatom communities for soil quality assessment. J. Appl. Phycol. 
470

Berg, A., Sheffield, J., 2018. Climate change and drought: the soil moisture perspective. Curr. Clim. Chang. Reports 4, 180-191. https://doi.org/10.1007/s40641-018-0095-0

Bohne, F., Linden, H., 2002. Regulation of carotenoid biosynthesis genes in response to light in Chlamydomonas reinhardtii. Biochim. Biophys. Acta - Gene Struct. Expr. 1579, 26-34. https://doi.org/10.1016/S0167-4781(02)00500-6

Boney, A.D., 1980. Water retention and radiation transmission by gelatinous strata of the saccoderm desmid Mesotaenium chlamydosporum De Bary. Nov. Hedwigia 33, 949-970.

Booth, W.E., 1941. Algae as pioneers in plant succession and their importance in erosion control. Ecology 22, 38-46. https://doi.org/10.2307/1930007

Camburn, K.E., 1982. Subaerial diatom communities in eastern Kentucky. Trans. Am. Microsc. Soc. 101, 375-387. https://doi.org/10.2307/3225756

Cartaxana, P., Brotas, V., 2003. Effects of extraction on HPLC quantification of major pigments from benthic microalgae. Arch. fur Hydrobiol. 157, 339-349. https://doi.org/10.1127/00039136/2003/0157-0339

Chambers, J.M., Cleveland, W.S., Kleiner, B., Tukey, P.A., 1983. Graphical methods for data analysis. Wadsworth \& Brooks/Cole.

Corine Land Cover. 2018. Corine Land Cover. Available at https://land.copernicus.eu/paneuropean/corine-land-cover/clc2018 (accessed 6 November 2019).

Davey, M.C., 1991. The seasonal periodicity of algae on Antarctic fellfield soils. Holarct. Ecol. 14, 112-120. https://doi.org/10.1111/j.1600-0587.1991.tb00641.x 
491 Davey, M.C., Rothery, P., 1992. Factors causing the limitation of growth of terrestrial algae in 492 maritime Antarctica during late summer. Polar Biol. 12, 595-601. https://doi.org/10.1007/BF00236982

494

495

496

497

498

499

500

501

502

503

504

505

506

507

508

509

510

511

512

Demmig-Adams, B., Adams, W.W., 2000. Harvesting sunlight safely. Nature 403, 371-373. https://doi.org/10.1038/35000315

Duong, T.T., Nguyen, H.Y., Le, T.P.Q., Nguyen, T.K., Tran, T.T.H., Le, N. Da, Dang, D.K., Vu, T.N., Panizzo, V., McGowan, S., 2019. Transitions in diatom assemblages and pigments through dry and wet season conditions in the Red River, Hanoi (Vietnam). Plant Ecol. Evol. 152, 163-177. https://doi.org/10.5091/plecevo.2019.1627

Fernandes, A.S., do Nascimento, T.C., Jacob-Lopes, E., Rosso, V.V. De, Queiroz, Zepka, L., 2018. Introductory chapter: Carotenoids - A brief overview on its structure, biosynthesis, synthesis, and applications, in: Zepka, L.Q., Jacob-Lopes, E., Rosso, V.V. De (Eds.), Progress in Carotenoid Research. IntechOpen, Rijeka. https://doi.org/10.5772/intechopen.79542

Foets, J., Wetzel, C.E., Teuling, A.J., Pfister, L., 2020. Temporal and spatial variability of terrestrial diatoms at the catchment scale : controls on communities. PeerJ 1-19. https://doi.org/10.7717/peerj.8296

Fritsch, F.E., 1907. The role of algal growth in the colonization of new ground and in the determination of scenery. Geogr. J. 30, 531-548. https://doi.org/10.2307/1778061

Grondin, A.E., Johansen, J.R., 1995. Seasonal succession in a soil algal community associated with a beech-maple forest in northeastern Ohio, USA. Nov. Hedwigia 60, 1-12.

Hill, M.O., Gauch, H.G., 1980. Detrended correspondence analysis: an improved ordination 
technique. Vegetatio 42, 47-58. https://doi.org/10.1007/978-94-009-9197-2_7

514 Hinder, S.L., Hays, G.C., Edwards, M., Roberts, E.C., Walne, A.W., Gravenor, M.B., 2012.

515 Changes in marine dinoflagellate and diatom abundance under climate change. Nat. Clim.

516 Chang. 2, 271-275. https://doi.org/10.1038/nclimate1388

517 Hoffmann, L., 1989. Algae of terrestrial habitats. Bot. Rev. 55, 77-105.

$518 \quad$ https://doi.org/10.1007/BF02858529

519 Houba, V.J.G., Temminghoff, E.J.M., Gaikhorst, G.A., van Vark, W., 2000. Soil analysis

520 procedures using 0.01 M calcium chloride as extraction reagent. Commun. Soil Sci. Plant

$521 \quad$ Anal. 31, 1299-1396. https://doi.org/10.1080/00103620009370514

522 ISO 10390, 2005. Soil quality - Determination of pH. Geneva, Switzerland.

523 Jewson, D.H., Lowry, S.F., Bowen, R., 2006. Co-existence and survival of diatoms on sand 524 grains. Eur. J. Phycol. 41, 131-146. https://doi.org/10.1080/09670260600652903

525 Johansen, J.R., 1993. Cryptogamic crusts of semiarid and arid lands of North America. J. Phycol.

$526 \quad 29,140-147$. https://doi.org/10.1111/j.0022-3646.1993.00140.x

527 Karsten, U., Holzinger, A., 2014. Green algae in alpine biological soil crust communities:

528 Acclimation strategies against ultraviolet radiation and dehydration. Biodivers. Conserv. 23, 529 1845-1858. https://doi.org/10.1007/s10531-014-0653-2

530 Kuczynska, P., Jemiola-Rzeminska, M., Strzalka, K., 2015. Photosynthetic pigments in diatoms.

$531 \quad$ Mar. Drugs 13, 5847-5881. https://doi.org/10.3390/md13095847

532 Kuznetsova, A., Brockhoff, P.B., Christensen, R.H.B., 2017. 1merTest Package: Tests in Linear

$533 \quad$ Mixed Effects Models._J. Stat. Softw., 82 (13), 1-26. doi: 10.18637/jss.v082.i13

534 Leavitt, P.R., Hodgson, D.A., 2001. Sedimentary pigments, in: Smol, J.P., Birks, H.J.B., Last, 
W.M. (Eds.), Tracking Environmental Change Using Lake Sediments. Volume 3:

536

Terrestrial, algal, and siliceous indicators. Kluwer Academic Publishers, Dordrecht, pp.

537 295-327. https://doi.org/10.1007/0-306-47668-1

538

Lecointe, C., Coste, M., Prygiel, J., 1993. "Omnidia”': software for taxonomy, calculation of 539 diatom indices and inventories management. Hydrobiologia 269, 509-513.

540 https://doi.org/10.1007/BF00028048

Legendre, P., Borcard, D., Peres-Neto, P.R. 2005. Analyzing beta diversity: partitioning the spatial variation of community composition data. Ecol. Monogr. 75, 435-450. https://doi.org/10.1890/05-0549

Lowe, R.L., Furey, P.C., Ress, J.A., Johansen, J.R., 2007. Diatom biodiversity and distribution on wetwalls in Great Smoky Mountains National Park. Southeast. Nat. 6, 135-153. https://doi.org/10.1656/1528-7092(2007)6[135:DBADOW]2.0.CO;2

547

548

549

550

551

552

553

554

555

556

Lund, J.W.G., 1945. Observations on soil algae I: the ecology, size and taxonomy of Bristish soil diatoms: part 1. New Phytol. 44, 196-219. https://doi.org/10.1111/j.14698137.1945.tb05033.x

Meteolux, 2019. Weather report of 2018. Available at

https://www.meteolux.lu/fr/filedownload/73/luxembourg_wmo_06590_ta_rr_climatebulletin_20 18.pdf/type/pdf (accessed 07 January 2020).

Neidhardt, J., Benemann, J.R., Zhang, L., Melis, A., 1998. Photosystem-II repair and chloroplast recovery from irradiance stress: relationship between chronic photoinhibition, lightharvesting chlorophyll antenna size and photosynthetic productivity in Dunaliella salina (green algae). Photosynth. Res. 56, 175-184. https://doi.org/10.1023/A:100602482 
557 Nychka D, Furrer R, Paige J, Sain S. 2017. fields: Tools for spatial data. Available at

558 https://cran.r-project.org/web/packages/fields/index.html.

559 Oksanen, J., Blanchet, F.G., Friendly, M., Kindt, R., Legendre, P., McGinn, D., Minchin, P.R.,

560 O’Hara, R.B., Simpson, G.L., Solymos, P., Stevens, M.. H.H., Szoecs, E., Wagner, H.,

561 2019. Vegan: community ecology package. R package version 2.5-5.

562 Paterson, D.M., 1986. The migratory behaviour of diatom assemblages in a laboratory tidal 563 scanning electron microscopy micro-ecosystem examined by low temperature. Diatom Res.

564

565

566

567

568

Pfister, L., Martínez-Carreras, N., Hissler, C., Klaus, J., Carrer, G.E., Stewart, M.K., McDonnell, 1, 227-239. https://doi.org/10.1080/0269249X.1986.9704971

Pringsheim, E.G., 1951. The soil-water culture technique of growing algae, in: Brunel, J.,

570 Prescott, G.W., Tiffany, L.H. (Eds.), The culturing of algae. The Charles F. Kettering Foundation, Ohoi. pp. 19-26.

Quesada, A., Vincent, W.F., 1993. Adaptation of cyanobacteria to the light regime within Antarctic microbial mats. SIL Proceedings, 1922-2010 25, 960-965. https://doi.org/10.1080/03680770.1992.11900293

Reavie, E.D., Edlund, M.B., Andresen, N.A., Engstrom, D.R., Leavitt, P.R., Schottler, S., Cai, M., 2017. Paleolimnology of the Lake of the Woods southern basin: continued water quality degradation despite lower nutrient influx. Lake Reserv. Manag. 33, 369-385. https://doi.org/10.1080/10402381.2017.1312648 
579 Ress, J.A., 2012. The ecology of aerial algae, bgsu1332874801. D. Phil. Thesis, Bowling Green

580 State University. Available at https://etd.ohiolink.edu/pg_10?0:

581 Rimet, F., Bouchez, A., 2012. Life-forms, cell-sizes and ecological guilds of diatoms in

582 European rivers. Knowl. Manag. Aquat. Ecosyst. 406, 1-12.

$583 \quad$ https://doi.org/10.1051/kmae/2012018

584 Rindi, F., 2011. Terrestrial green algae: Systematics, biogeography and expected responses to

585 climate change, in: Hodkinson, T.R., Jones, M.B., Waldren, S., Parnell, J.A.N. (Eds.),

586 Climate change, ecology and systematics. Cambridge University Press, pp. 201-228.

587 https://doi.org/10.1017/CBO9780511974540.010

588 Round, F.E., Crawford, R.M., Mann, D.G., 1990. The diatoms. Biology and morphology of the 589 genera. Cambridge University Press, Cambridge.

590 Scarsini, M., Marchand, J., Manoylov, K.M., Schoefs, B., 2019. Photosynthesis in diatoms, in:

591 Seckbach, J., Gordon, R. (Eds.), Diatoms: fundamentals and applications. Scrivener

592 Publishing LLC, New Jersey, pp. 191-211. https://doi.org/10.1002/9781119370741

593 Schagerl, M., Künzl, G., 2007. Chlorophyll a extraction from freshwater algae - A reevaluation.

594 Biologia (Bratisl). 62, 270-275. https://doi.org/10.2478/s11756-007-0048-X

595 Schmidt, O., Dyckmans, J., Schrader, S., 2016. Photoautotrophic microorganisms as a carbon $596 \quad$ source for temperate soil invertebrates. Biol. Lett. 12.

597 https://doi.org/10.1098/rsbl.2015.0646

598 Shephard, K.L., 1987. Evaporation of water from the mucilage of a gelatinous algal community.

599 Br. Phycol. J. 22, 181-185. https://doi.org/10.1080/00071618700650221

600 Shubert, L.E., Starks, T.L., 1979. Algal succession on orphaned coal mine spoils. Ecol. coal 
601

Resour. Dev. 2, 661-669. https://doi.org/10.1016/B978-1-4832-8365-4.50089-2

602 Smol, J.P., Stoermer, E.F., 2010. The diatoms: applications for the environmental and earth 603 sciences. Cambridge University Press, Cambridge.

604 Souffreau, C., Vanormelingen, P., Sabbe, K., Vyverman, W., 2013. Tolerance of resting cells of 605 freshwater and terrestrial benthic diatoms to experimental desiccation and freezing is 606 habitat-dependent. Phycologia 52, 246-255. https://doi.org/10.2216/12-087.1

607 Stanek-Tarkowska, J., Noga, T., Pajączek, A., Peszek, U., 2013. The occurrence of Sellaphora 608 nana (Hust.) LangeBert. Cavacini, Tagliaventi \& Alfinito, Stauroneis borrichii (J.B. 609 Petersen) J.W.G. Lund, S. parathermicola Lange-Bert. and S. thermicola (J.B. Petersen) 610 J.W.G. Lund on agricultural soils. Algol. Stud. 142, 109-119. https://doi.org/10.1127/1864-1318/2013/0114

Starks, T.L., Shubert, L.E., 1982. Colonization and succession of algae and soil-algal interactions associated with disturbed areas. J. Phycol. 18, 99-107. https://doi.org/10.1111/j.1529-

614 8817.1982.tb03162.x 65-80. https://doi.org/10.2216/i0031-8884-20-1-65.1

Stokes, J.L., 1940. The influence of environmental factors upon the development of algae and other micro-organisms in soil. Soil Sci. 49, 171-184. https://doi.org/10.1097/00010694-

619 194003000-00002

Takaichi, S., 2011. Carotenoids in algae: Distributions, biosyntheses and functions. Mar. Drugs 9, 1101-1118. https://doi.org/10.3390/md9061101

622 Tolhurst, T.J., Gust, G., Paterson, D.M., 2002. The influence of an extracellular polymeric 
623

624

625

626

627

628

629

630

631

632

633

634

635

636

637

638

639

640

641

642

643

644

substance (EPS) on cohesive sediment stability. Proc. Mar. Sci. 5, 409-425. https://doi.org/10.1016/S1568-2692(02)80030-4

Van de Vijver, B., Beyens, L., 1997. The epiphytic diatom flora of mosses from Strømness Bay area, South Georgia. Polar Biol. 17, 492-501. https://doi.org/10.1007/s003000050148

Van de Vijver, B., Ledeganck, P., Beyens, L., 2002. Soil diatom communities from Ile de la Possession (Crozet, sub-Antarctica). Polar Biol. 25, 721-729. https://doi.org/10.1007/s00300-002-0392-9

Verleyen, E., Hodgson, D.A., Leavitt, P.R., Sabbe, K., Vyverman, W., 2004. Quantifying habitat-specific diatom production: A critical assessment using morphological and biogeochemical markers in Antarctic marine and lake sediments. Limnol. Oceanogr. 49, 1528-1539. https://doi.org/10.4319/1o.2004.49.5.1528

Vincent, W.F., 2000. Cyanobacterial dominance in the polar regions, in: Whitton, B.A., Potts, M. (Eds.), The ecology of cyanobacteria: their diversity in time and space. Academic publishers, Dordrecht, pp. 321-340. https://doi.org/10.1007/0-306-46855-7

Wu, Y., Rao, B., Wu, P., Liu, Y., Li, G., Li, D., 2013. Development of artificially induced biological soil crusts in fields and their effects on top soil. Plant Soil 370, 115-124. https://doi.org/10.1007/s11104-013-1611-6

Xia, S., Wang, K., Wan, L., Li, A., Hu, Q., Zhang, C., 2013. Production, characterization, and antioxidant activity of fucoxanthin from the marine diatom odontella aurita. Mar. Drugs 11, 2667-2681. https://doi.org/10.3390/md11072667

Zhang, Z., Lv, Y., Pan, H., 2013. Cooling and humidifying effect of plant communities in subtropical urban parks. Urban For. Urban Green. 12, 323-329. 
645 https://doi.org/10.1016/j.ufug.2013.03.010 
Figure 1

Land use characteristics of the Attert River Basin in Luxembourg and Belgium.

The map shows the 16 sampling locations. Source: modified from Corine Land Cover (2018).

- Coniferous forest Broad-leaved forest Mixed forest Grassland Agricultural area Urban area

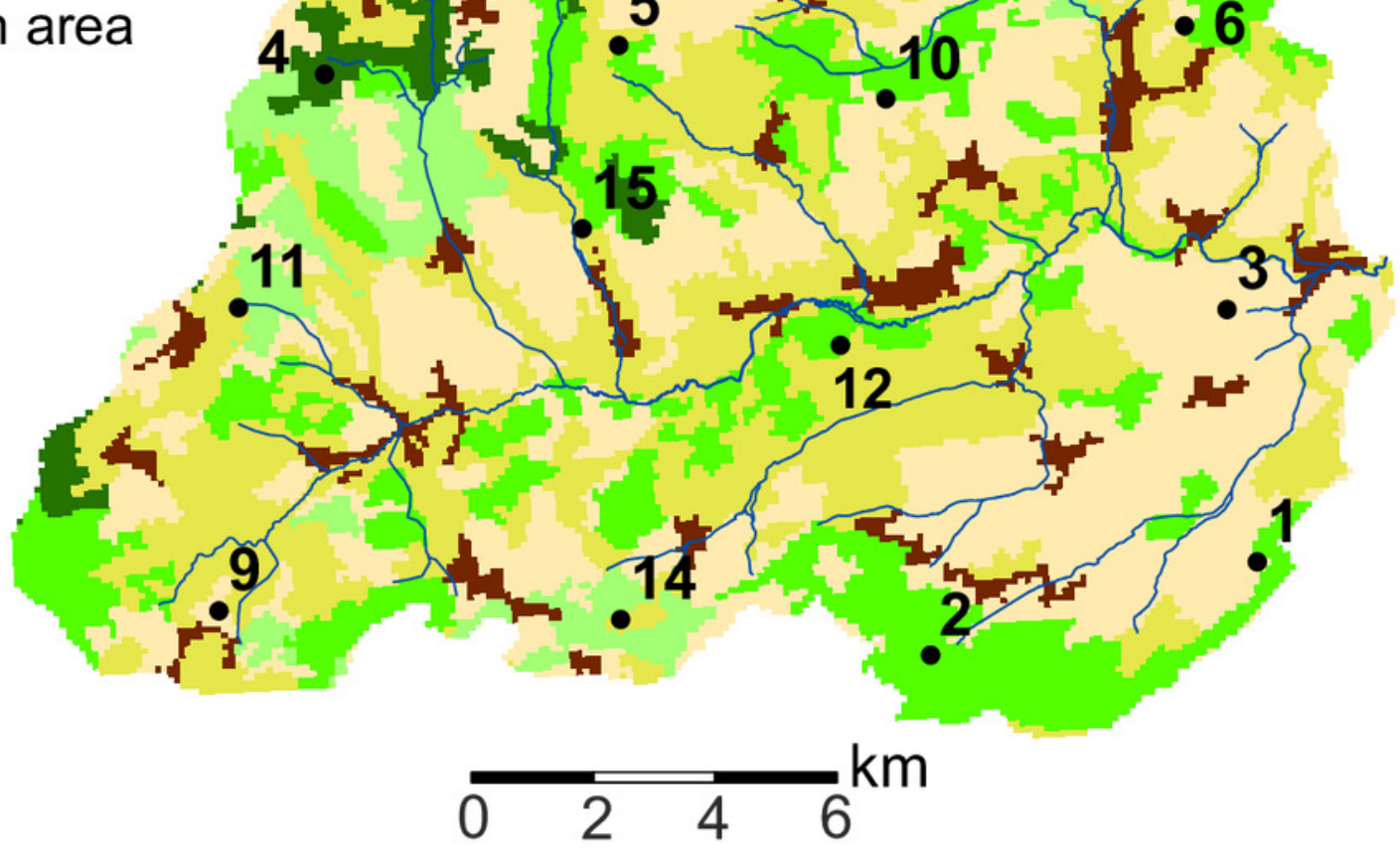




\section{Table $\mathbf{1}$ (on next page)}

Summary of proxies employed in this study.

Cy, Cyanophyta (cyanobacteria); E, Euglenophyta; CL, Chlorophyta ( green algae); B, Bacillariophyceae ( diatoms); R, Rhodophyta; X, Xanthophyceae. *, major carotenoid in most species of the class. Table derived from Verleyen et al. (2004) and Takaichi (2011). 


\begin{tabular}{|c|c|c|c|}
\hline Pigment & Code & Affinity & Interpretation \\
\hline $\begin{array}{l}\text { Chlorophyll a (incl. } \\
\text { derivatives) }\end{array}$ & TChla & All photosynthetic algae & $\begin{array}{l}\text { Primary production/Total algal } \\
\text { production }\end{array}$ \\
\hline Fucoxanthin & Fx & $\mathrm{B}^{*}$ & Diatom production \\
\hline Diatoxanthin & $\mathrm{Da}$ & $\mathrm{B}, \mathrm{X}^{*}, \mathrm{E}$ & Diatoms, measure for irradiance \\
\hline Diadinoxanthin & Dd & $\mathrm{B}, \mathrm{X}^{*}, \mathrm{E}^{*}$ & Diatoms, measure for irradiance \\
\hline Zeaxanthin & $\mathrm{Ze}$ & $\mathrm{Cy}^{*}, \mathrm{R}^{*}, \mathrm{~B}, \mathrm{E}, \mathrm{Cl}$ & Cyanobacteria production \\
\hline $\begin{array}{l}\text { Lutein } \\
(\mathrm{Dd}+\mathrm{Da}) \mathrm{Fx}^{-1}\end{array}$ & $\mathrm{Lu}$ & $\mathrm{Cl}^{*}$ & $\begin{array}{l}\text { Green algal production } \\
\text { Mean irradiance per diatom }\end{array}$ \\
\hline
\end{tabular}

1 


\section{Table 2 (on next page)}

Element distribution for two example points.

Weight percentages are derived from the scanning electron analysis from two points indicated in Fig. 2F. The weight percentage of an element is the weight of that element measured in the sample divided by the weight of all elements in the sample multiplied by 100. 


\begin{tabular}{|lll|}
\hline Element & EDS 1 (\%) & EDS 2 (\%) \\
\hline $\mathrm{C}$ & 22.7 & 12.5 \\
$\mathrm{~N}$ & 3.0 & \\
$\mathrm{O}$ & 36.2 & 24.5 \\
$\mathrm{Mg}$ & 0.4 & 0.8 \\
$\mathrm{Al}$ & 3.4 & 11.0 \\
$\mathrm{Si}$ & 24.9 & 26.3 \\
$\mathrm{P}$ & 0.4 & 0.3 \\
$\mathrm{~S}$ & 0.4 & 0.3 \\
$\mathrm{~K}$ & 3.2 & 6.1 \\
$\mathrm{Ca}$ & 1.4 & 2.9 \\
$\mathrm{Fe}$ & 4.0 & 5.5 \\
$\mathrm{Ti}$ & & 0.8 \\
\hline
\end{tabular}

1 


\section{Figure 2}

Illustration of diatoms living on the soil surface.

Images were taken with a Scanning Electron Microscope (SEM). The soil sample is from an agricultural grassland site (site 9, see Fig. 4 in Foets et al., 2020) sampled in November 2017. (A) Soil sample on aluminum stub. (B) SEM image. (C) Close-up of the dashed rectangle showing bacilli-shaped bacteria. (D) Life material showing pigment distribution in Hantzschia amphioxys (Ehrenberg) Grunow. (E) SEM picture showing external valve structures. (F) SEM picture showing the EDS 1 and EDS 2 analyzed zones. (G) SEM picture. (H) Chemical map showing oxygen concentration at the surface. (I) Chemical map showing silica concentration at the surface. 1, Sellaphora nana (Hustedt) Lange-Bertalot, Cavacini, Tagliaventi \& Alfinito; 2, Nitzschia pusilla (Kützing) Grunow emend. Lange-Bertalot; 3, H. amphioxys; 4, Mayamaea sp.; 5, bacteria. The scale bar is $10 \mu \mathrm{m}$ (if not indicated otherwise). Photo credit: Carlos E. Wetzel (A, D, E), Jean-Luc Biagi (B, F-I). 


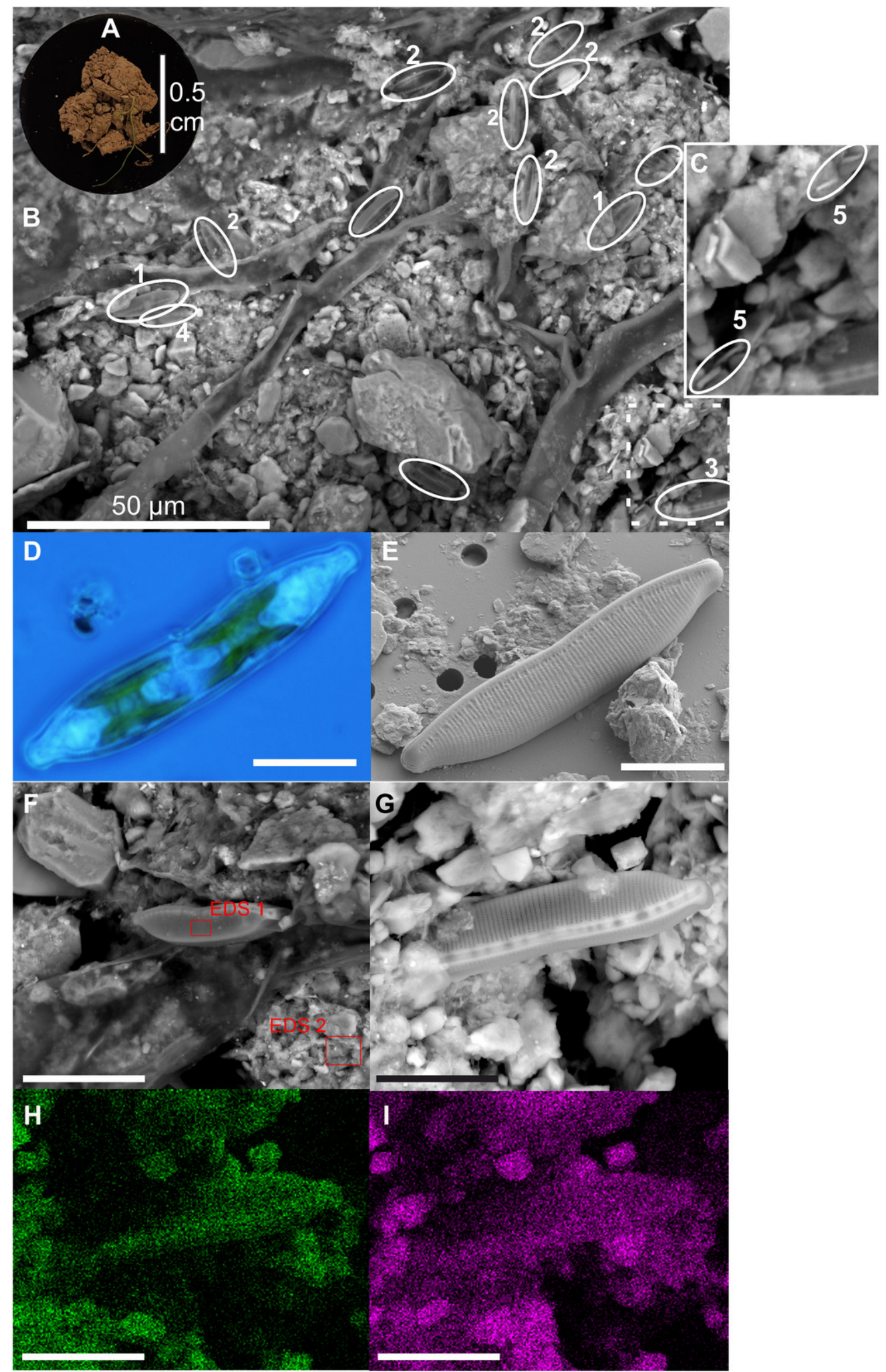


Figure 3

Impact of habitat type on algal concentrations and diatom biovolume.

(A) Concentration of diatoms, cyanobacteria and green algae. (B) Comparison of diatom biovolumes between habitat types. Biovolume is calculated according to Rimet $\&$ Bouchez (2012). AF, agricultural field; GG, grazed grassland; AG, agricultural grassland; UG, undisturbed grassland; F, forest. Not overlapping notches indicate that the medians differ (Chambers et al., 1983).
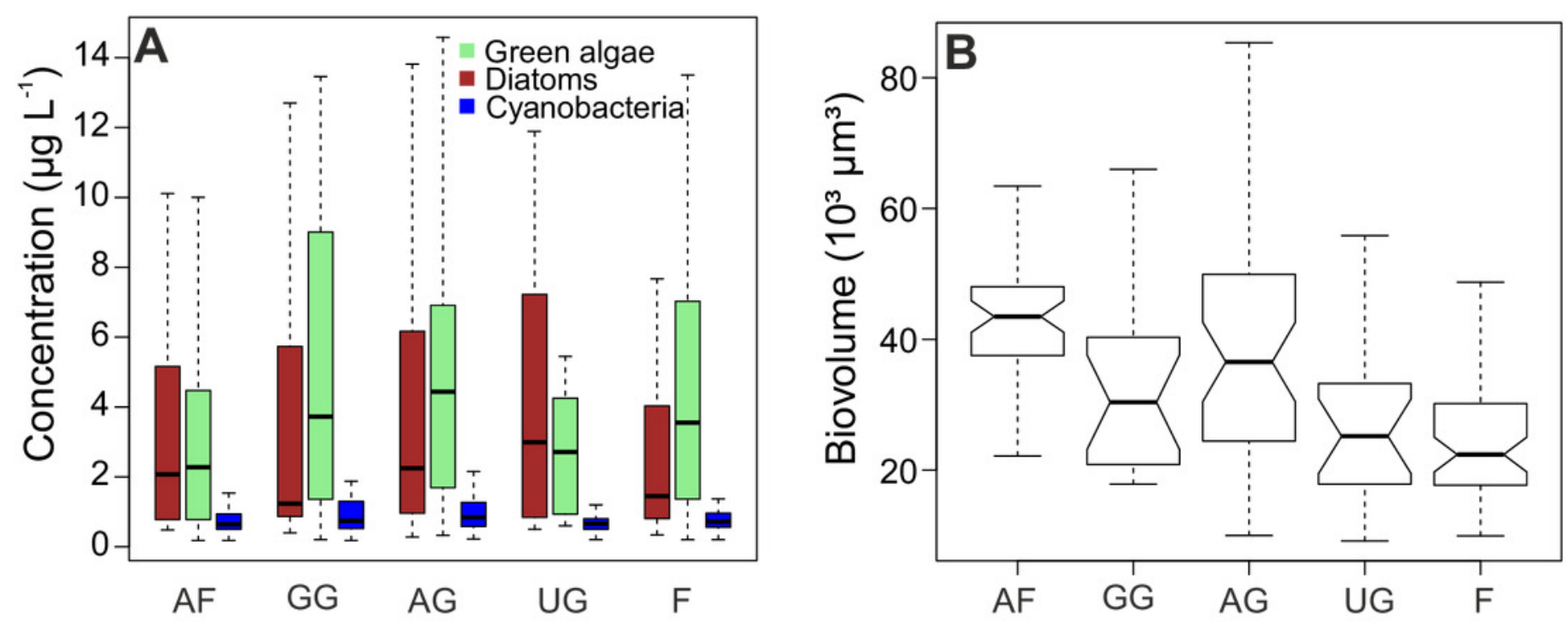
Figure 4

Results of redundancy analysis (RDA) on the relation between environmental variables and pigment data.

Pigment data is Hellinger transformed. Pigments: Fx, fucoxanthin; Lu, lutein; Ze, zeaxanthin; Dd, diadinoxanthin; Da, diatoxanthin. Variables: DOC, Dissolved organic carbon; Fe, iron; TN, total nitrogen; SD, storage deficit; P, phosphorus; Al, Aluminum; radiation, global radiation; moisture, soil moisture content.

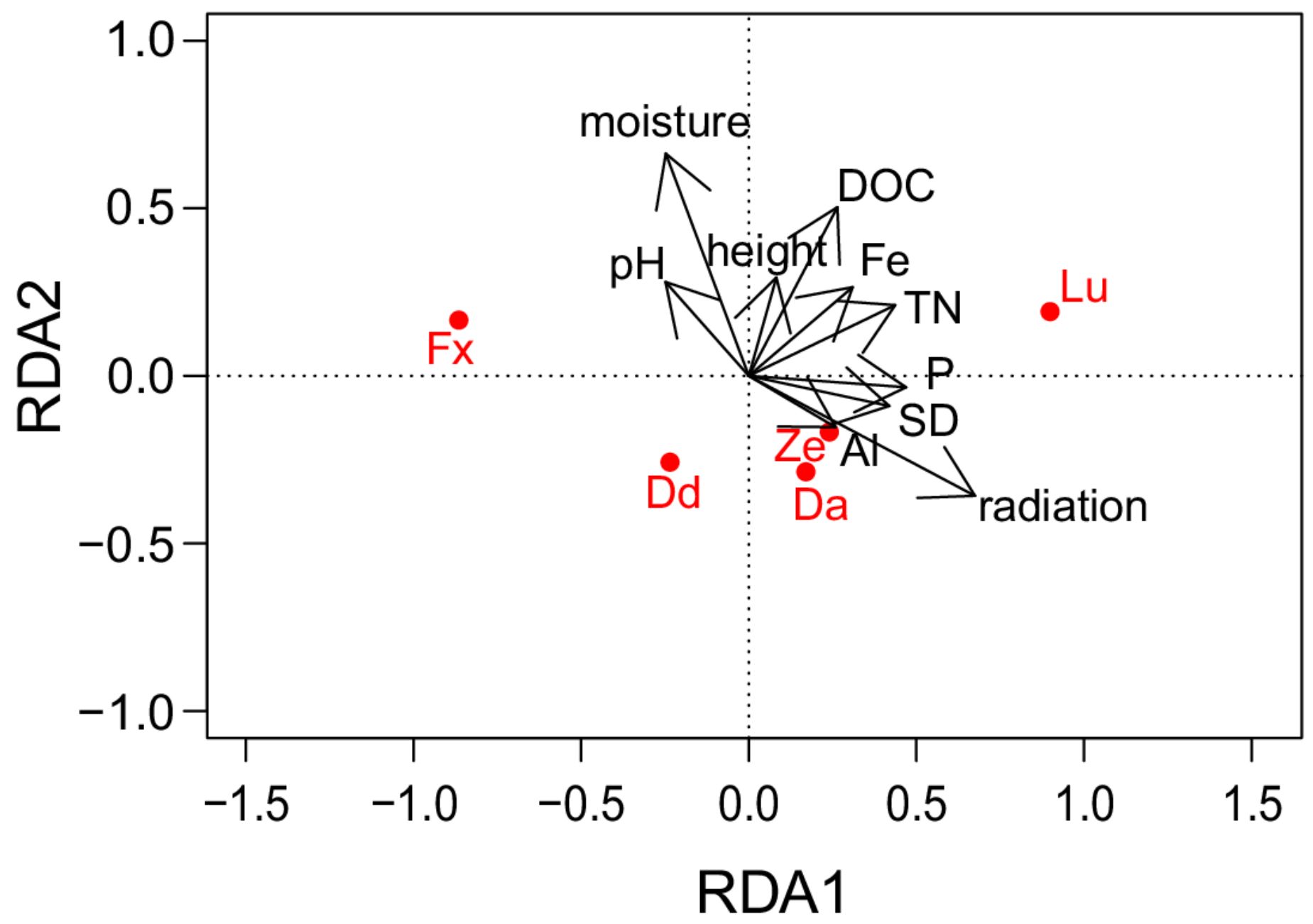




\section{Figure 5}

Variation partitioning of the pigment composition data.

Graph is represented as a Venn diagram, indicating three groups of variables (soil chemistry, site characteristics and meteorology) with their percentages of explained variance. The diagram shows the partitioning of the explained variance into seven components. A, partial effects of the soil chemistry; B, partial effects of the site characteristics; C, partial effects of meteorology; D, partial joint effects of soil chemistry and site characteristics; E, partial joint effects of soil chemistry and meteorology; F, partial joint effects of site characteristics and meteorology; G, partial joint effects of the three groups. Numbers outside the circles stand for the total variance (in percent) explained by each variable (including all joint effects). Meteorology includes air temperature, number of frozen days, precipitation, radiation, relative humidity, wind speed and PET. Soil chemistry includes $\mathrm{Na}, \mathrm{Mn}, \mathrm{Fe}, \mathrm{pH}, \mathrm{Si}, \mathrm{P}, \mathrm{DOC}, \mathrm{TN}$, $\mathrm{K}, \mathrm{Al}, \mathrm{Fe}$ and $\mathrm{Na}$. Site characteristics includes vegetation height, soil moisture content, site, type of habitat and level of disturbance. 


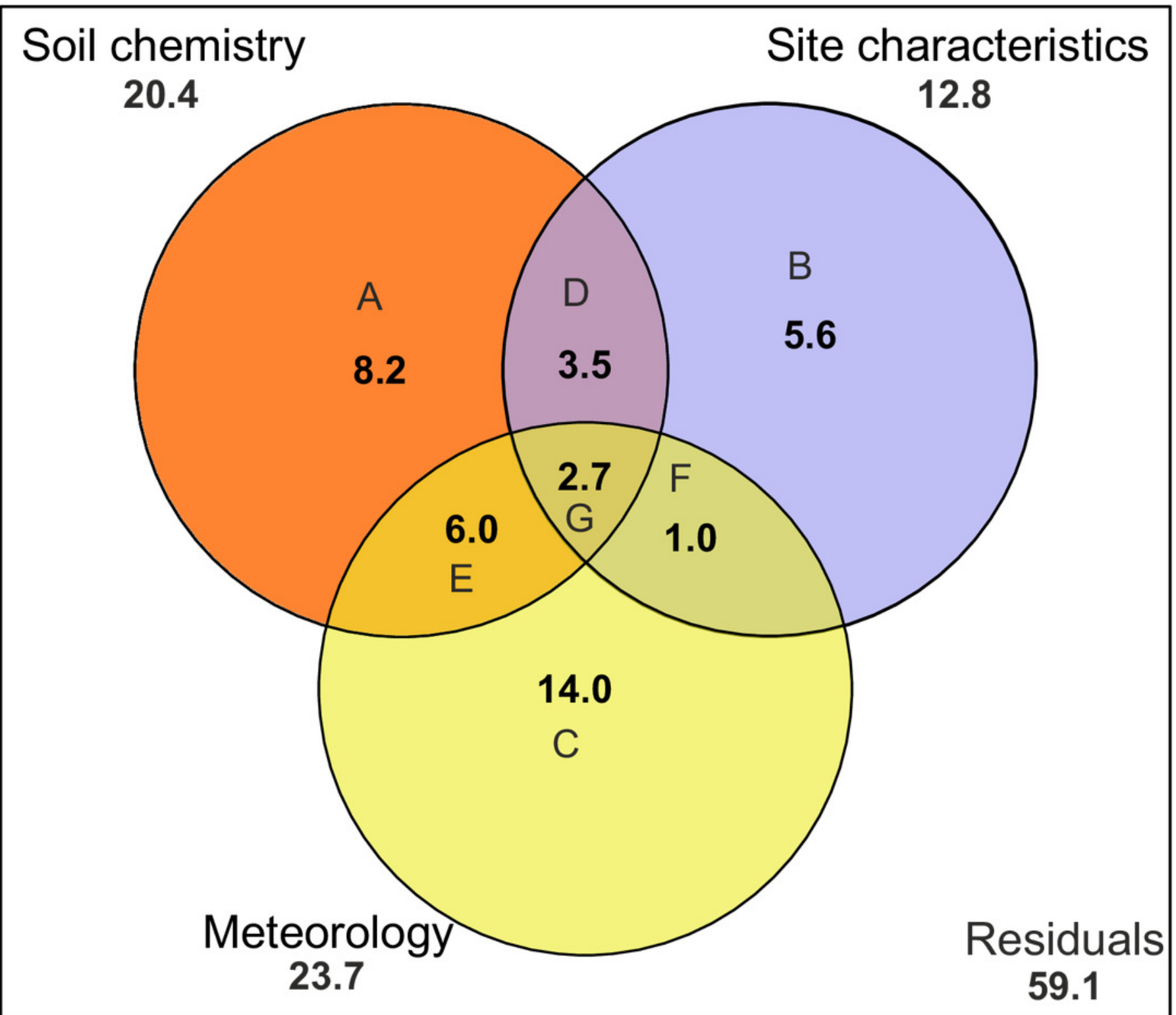




\section{Figure 6}

Temporal dynamics of atmospheric conditions and diatom characteristics during the sampling campaign.

(A) daily precipitation (blue bars) and air temperature (red line) fluctuations during the sampling campaign (1 December 2017-30 November 2018) retrieved from Useldange weather station (Luxembourg). (B) Temporal variation of green algal and diatom abundances. (C) Total algal production (TChla) and diatom biovolume. Diatom biovolume has been calculated according to Rimet \& Bouchez (2012). (D) Temporal variability of the ratio between the photoprotective $(\mathrm{Da}+\mathrm{Dd})$ and light-harvesting $(\mathrm{Fx})$ pigments of diatoms. 

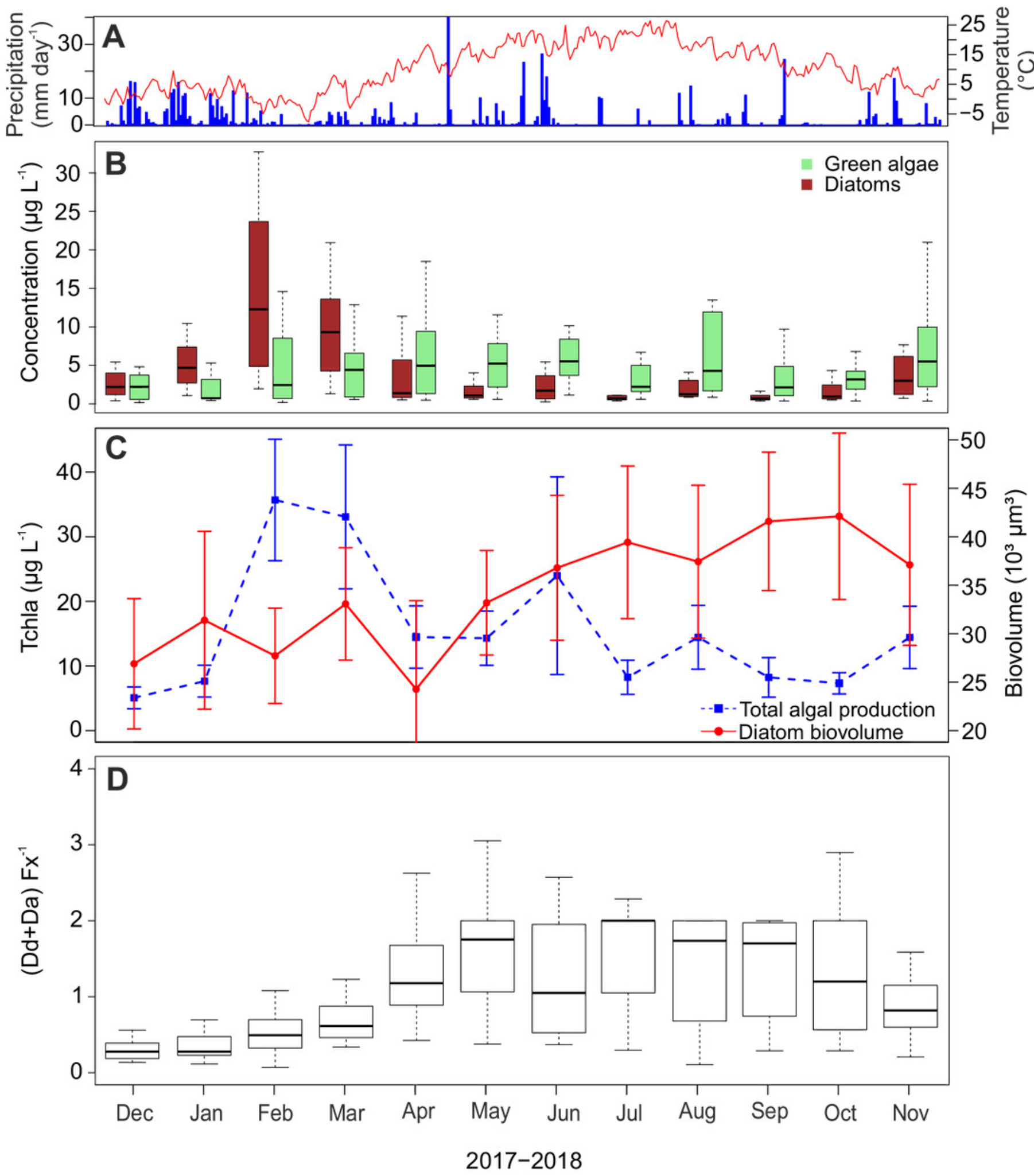